\title{
Análise e caracterização da bacia hidrográfica do córrego Fátima localizado no município de Frederico Westphalen-RS
}

\author{
Analysis and characterization of Fátima watershed located in the city of Frederico Westphalen-rs \\ Aline Hass', Sabrina Rodrigues da Conceição², Jessica Luana Henrichsen³ , Igor Brendler Chinazzo ${ }^{4}$, \\ Luciana Gregory Ritter ${ }^{5}$, Vanessa Deisi Renz ${ }^{6}$ \\ 1, 2, 3, 4, 6 Universidade Federal de Santa Maria, Santa Maria,RS, Brasil \\ ${ }_{5}^{5}$ Universidade Federal de Santa Maria, Frederico Westphalen, RS, Brasil
}

\section{Resumo}

A questão discutida no presente trabalho é a recuperação de Áreas de Preservação Permanente (APP) do córrego Fátima degradada pela ação humana, que se faz necessária para o resgate da biodiversidade e por força da Lei. A área de estudo localiza-se no bairro Fátima, no município de Frederico Westphalen, RS. Através de visitas realizadas ao local observou-se uma série de impactos ambientais. Diante desta preocupação em relação às áreas degradadas, o presente estudo visa o reflorestamento para recuperação do local e a conscientização da população para evitar futuras poluições.

Palavras-chave: Bacia hidrográfica, Impactos Ambientais, Recuperação.

\begin{abstract}
The question discussed in this paper is recovering Areas of Permanent Preservation (APP) stream Fatima degraded by human action, which is necessary for the recovery of biodiversity and by virtue of the Law. The study area is located in Fatima District, in the city of Frederico Westphalen, RS. Through visits to the local there was a series of impacts. Given this concern about the degraded areas, the present study aims to implement reforestation techniques for the place restoration and de population awareness to prevent future pollution.
\end{abstract}

Keywords: Watershed, Environmental Impacts, Recovery. 


\section{INTRODUÇÃO}

A água ocupa um lugar específico entre os recursos naturais. É a substância mais abundante no planeta, embora disponível em diferentes quantidades, em diferentes lugares. Possui papel fundamental no ambiente e na vida humana, e nada a substitui, pois sem ela a vida não pode existir.

SILVEIRA (2001) define a bacia hidrográfica como uma área de captação natural da água da precipitação que faz convergir os escoamentos para um único ponto de saída, seu exutório. É composta basicamente de um conjunto de superfícies vertentes e de uma rede de drenagem formada por cursos d'água que confluem até resultar um leito único no exutório.

Pelo caráter integrador, Guerra e Cunha (1996) citaram que as bacias hidrográficas são consideradas excelentes unidades de gestão dos elementos naturais e sociais, pois, nessa óptica, é possível acompanhar as mudanças introduzidas pelo homem e as respectivas respostas da natureza. Ainda de acordo com esses autores, em nações mais desenvolvidas a bacia hidrográfica também tem sido utilizada como unidade de planejamento e gerenciamento, compatibilizando os diversos usos e interesses pela água e garantindo sua qualidade e quantidade.

A delimitação de uma bacia hidrográfica é um dos primeiros e mais comuns procedimentos executados em análises hidrológicas ou ambientais. Para isso, tem sido comum a utilização de informações de relevo em formato analógico, como mapas e cartas, o que compromete a confiabilidade e a reprodução dos resultados devidos à carga de subjetividade inerente aos métodos manuais. Com o advento e consolidação dos Sistemas de Informações Geográficas e, consequentemente, o surgimento de formas digitais consistentes de representação do relevo, como os Modelos Digitais de Elevação (MDEs), métodos automáticos para delimitação de bacias têm sido desenvolvidos desde então (GARBRECHT e MARTZ, 1999).

A caracterização do meio físico da bacia hidrográfica, com o intuito de levantar todas as áreas críticas do ponto de vista da manutenção da água, é condição básica para um planejamento bem sucedido da conservação e produção de água. Segundo Pereira (1973), apud Lima (1986), a conservação da água não pode ser conseguida independentemente da conservação dos outros recursos naturais. O conhecimento das classes de declividade da bacia hidrográfica é importante porque visa atender à legislação específica para o ordenamento do uso da terra (ROSTAGNO, 1999). Além disso, a declividade tem relação importante com vários processos hidrológicos, tais como a infiltração, o escoamento superficial, a umidade do solo, etc. (LIMA, 1986).

Por constituírem ecossistemas com o predomínio de uma única saída, as bacias hidrográficas possibilitam a realização de uma série de experimentos (Valente \& Castro, 1981). As bacias hidrográficas também constituem ecossistemas adequados para avaliação dos impactos causados pela atividade antrópica que podem acarretar riscos ao equilíbrio e à manutenção da quantidade e a qualidade da água, uma vez que estas variáveis são relacionadas com o uso do solo (Fernandes \& Silva, 1994; Baruqui \& Fernandes, 1985).

\section{OBJETIVOS}

- Delimitar a bacia hidrográfica do Córrego Fátima.

- Identificar os impactos ambientais assim como seus agentes causadores.

- Apresentar uma proposta para recuperação da área de estudo.

\section{METODOLOGIA}

A Bacia hidrográfica está localizada nos seguintes locais: Rua Boa Esperança e Rua Brasília, no Bairro Fátima, município de Frederico Westphalen - RS (Figura 1), com coordenadas geográficas S: $27^{\circ} 21^{\prime} 33^{\prime \prime}$, W: $53^{\circ} 23^{\prime} 40^{\prime \prime}$, estando a uma altitude de 566 metros do nível do mar. 


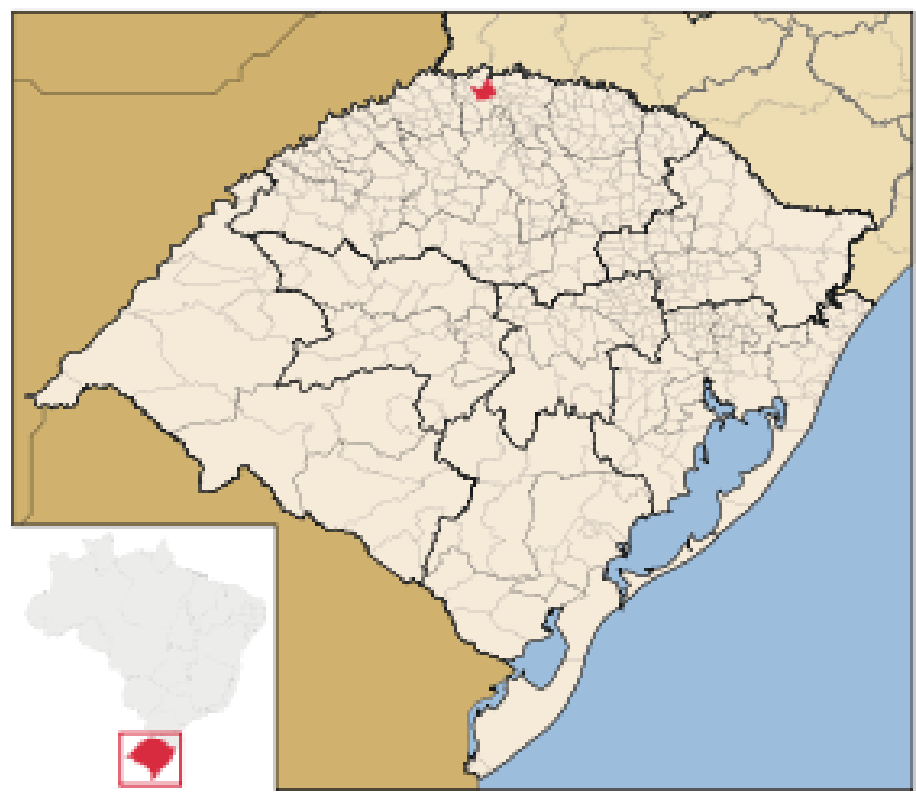

Figura 1: Município de Frederico Westphalen.

Fonte: http://pt.wikipedia.org/wiki/Frederico_Westphalen

Segundo a classificação de Köppen, o clima da cidade de Frederico Westphalen é do tipo Cfb, com temperaturas podendo atingir máximas de $41^{\circ} \mathrm{C}$ no verão e mínimas inferiores a $0^{\circ} \mathrm{C}$ no inverno, sendo que a temperatura média anual é em torno de $18^{\circ} \mathrm{C}$. A precipitação média anual varia entre 1.800 e $2.100 \mathrm{~mm}$, bem distribuídos durante o ano (Bernardi et al., 2008).

A área total da bacia é de $1,931 \mathrm{Km} 2$, situada na zona urbana, em área residencial (Figura 2).

A metodologia adotada para execução do trabalho é referente à caracterização da área de estudo quanto a dados geográficos e observações realizadas.

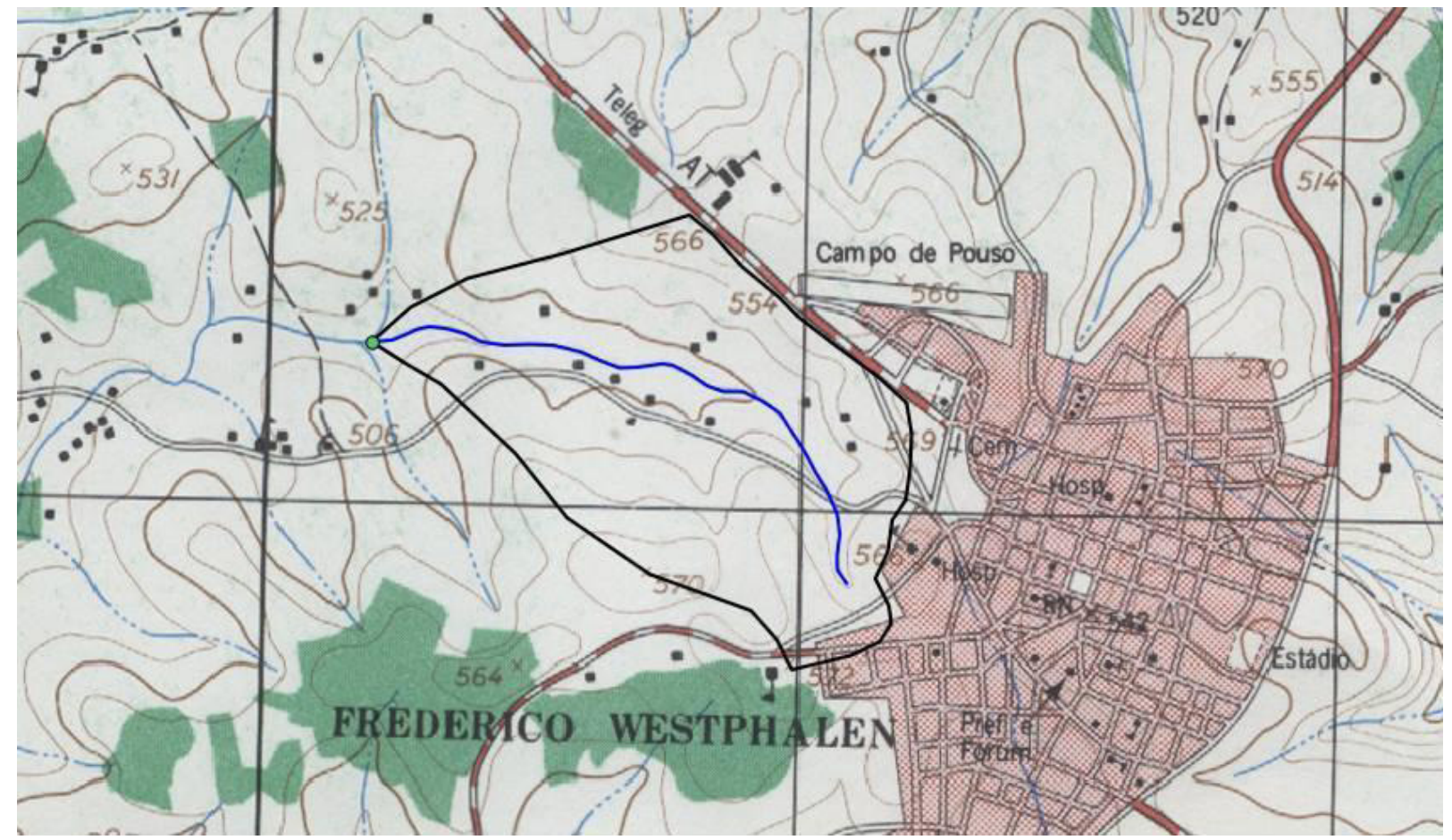

Figura 2: Delimitação da Bacia

Fonte: Quantum GIS 1.8.0 - Lisboa 


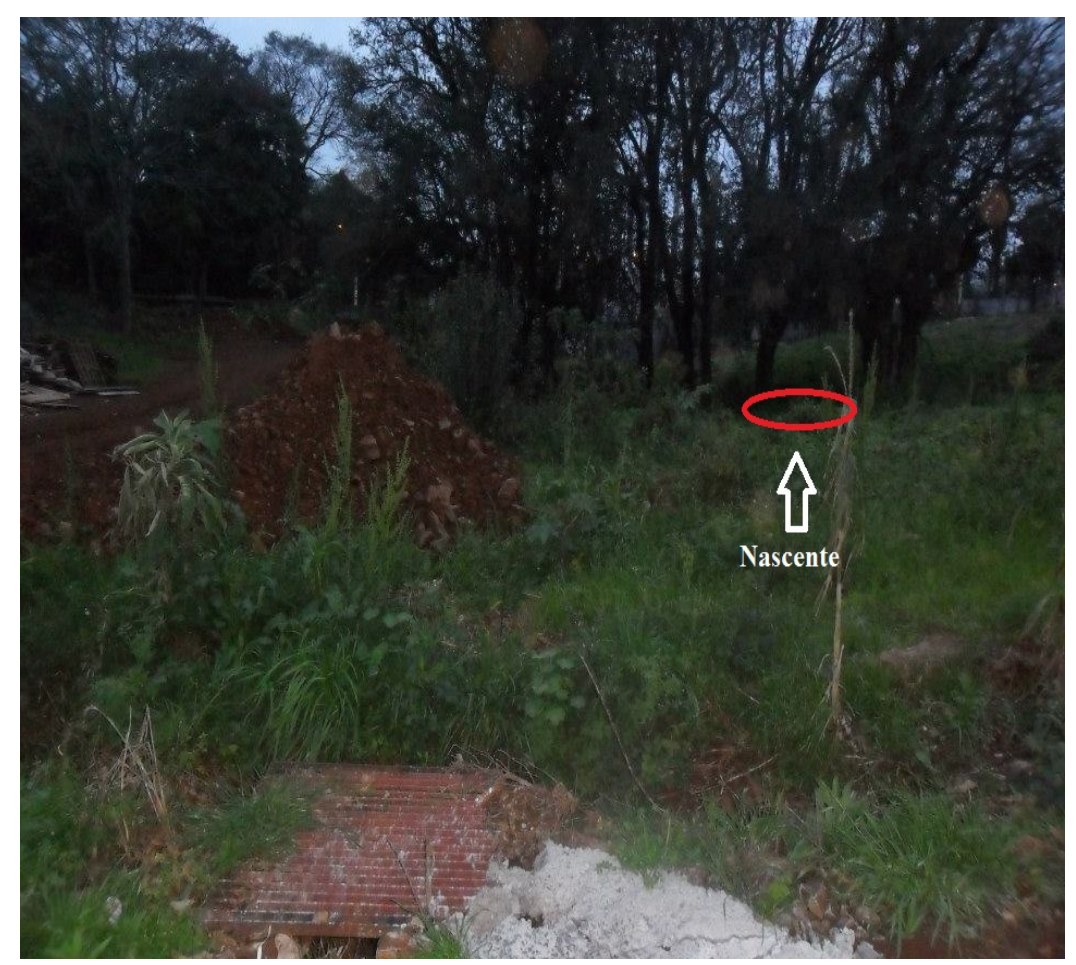

Figura 3: Nascente 1.

Fonte: Autor

Realizou-se uma visita à área de estudo para o reconhecimento e análise do local. Onde pode-se perceber a presença de vários agentes impactantes, degradação e descaso da população com o curso d'água e também com as duas nascentes.

A nascente 1, localizada na Rua Boa Esperança, é de fluxo intermitente. Encontra-se praticamente abandonada, com resíduos de construção civil e pouca vegetação (figura 3 ).

No decorrer do curso d'água, observa-se disposição de resíduos domiciliares, de construção civil, incluindo materiais de dificil degradação como: sacos e copos plásticos, latas de alumínio, isopor, entre outros (Figura 4).

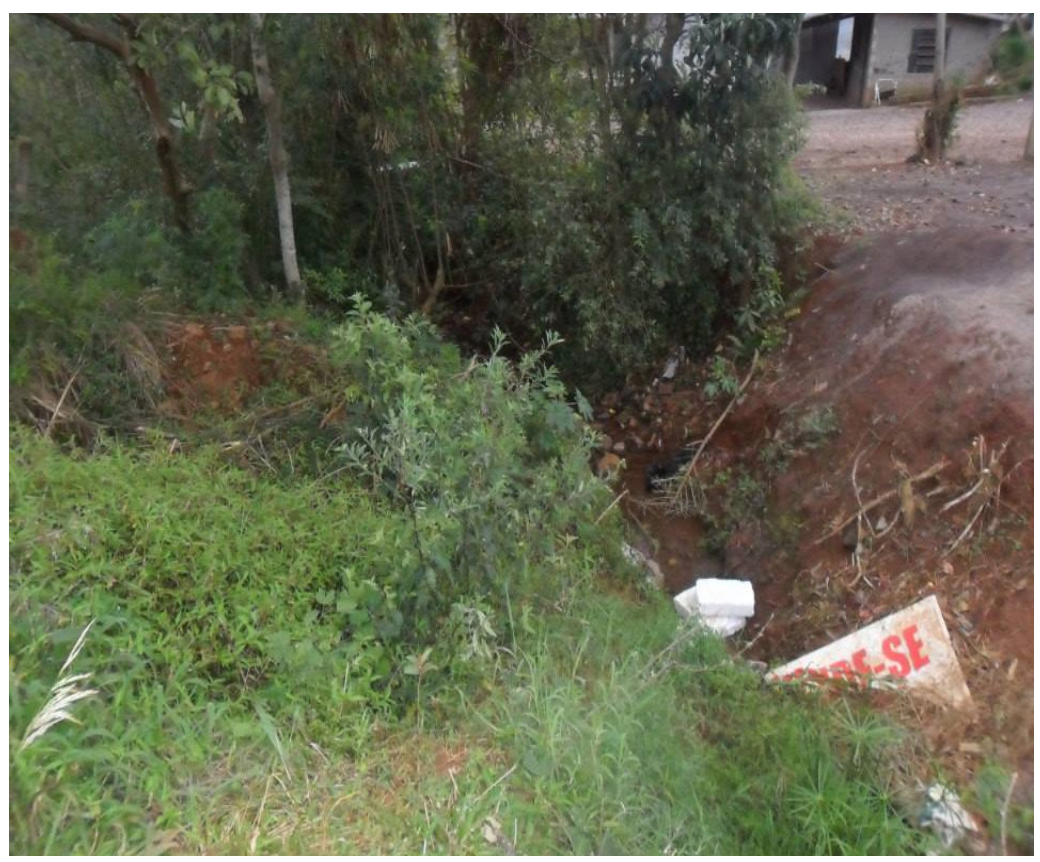

Figura 4: Disposição de resíduos.

Fonte: Autor. 


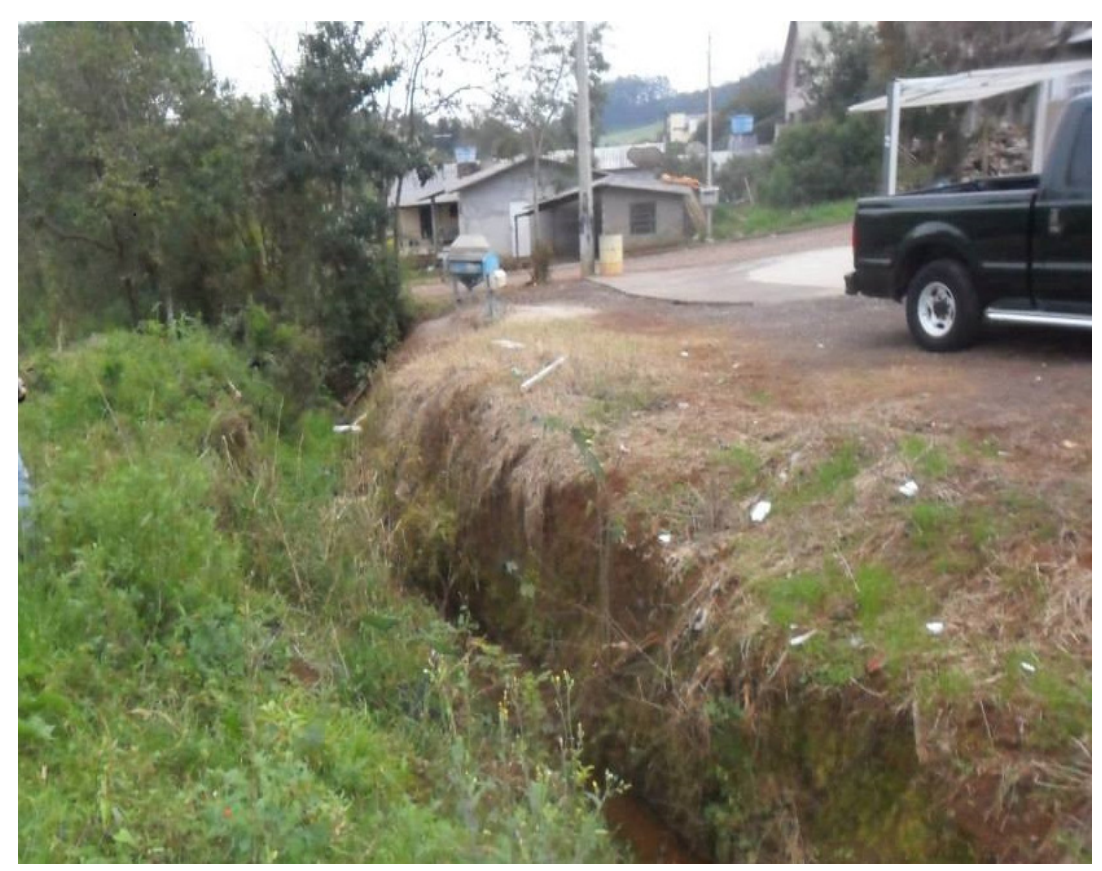

Figura 5: Moradias em locais inadequados.

Fonte: Autor.

Além disso, observou-se que a área apresenta problemas como o solo descoberto, falta de vegetação marginal onde há residências nas proximidades do local (Figura 5), o que não está de acordo com as conformidades da lei. Segundo o Novo Código Florestal - Lei ${ }^{\circ}$ 12.651, de 25 de maio de 2012:

Art. $4^{\circ}$ Considera-se Área de Preservação Permanente, em zonas rurais ou urbanas, para os efeitos desta Lei:

I - as faixas marginais de qualquer curso d'água natural, desde a borda da calha do leito regular, em largura mínima de:

a) 30 (trinta) metros, para os cursos d'água de menos de 10 (dez) metros de largura [...].

IV - as áreas no entorno das nascentes e dos olhos d'água, qualquer que seja a sua situação topográfica, no raio mínimo de 50 (cinquenta) metros [...].

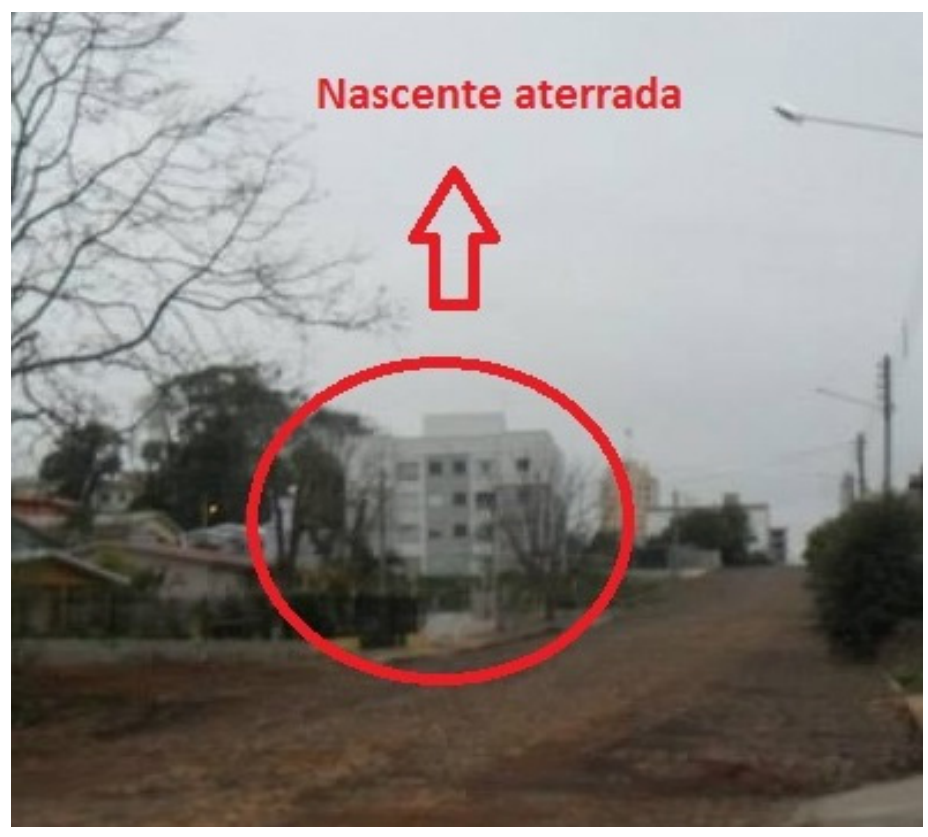

Figura 6: Nascente 2.

Fonte: Autor. 


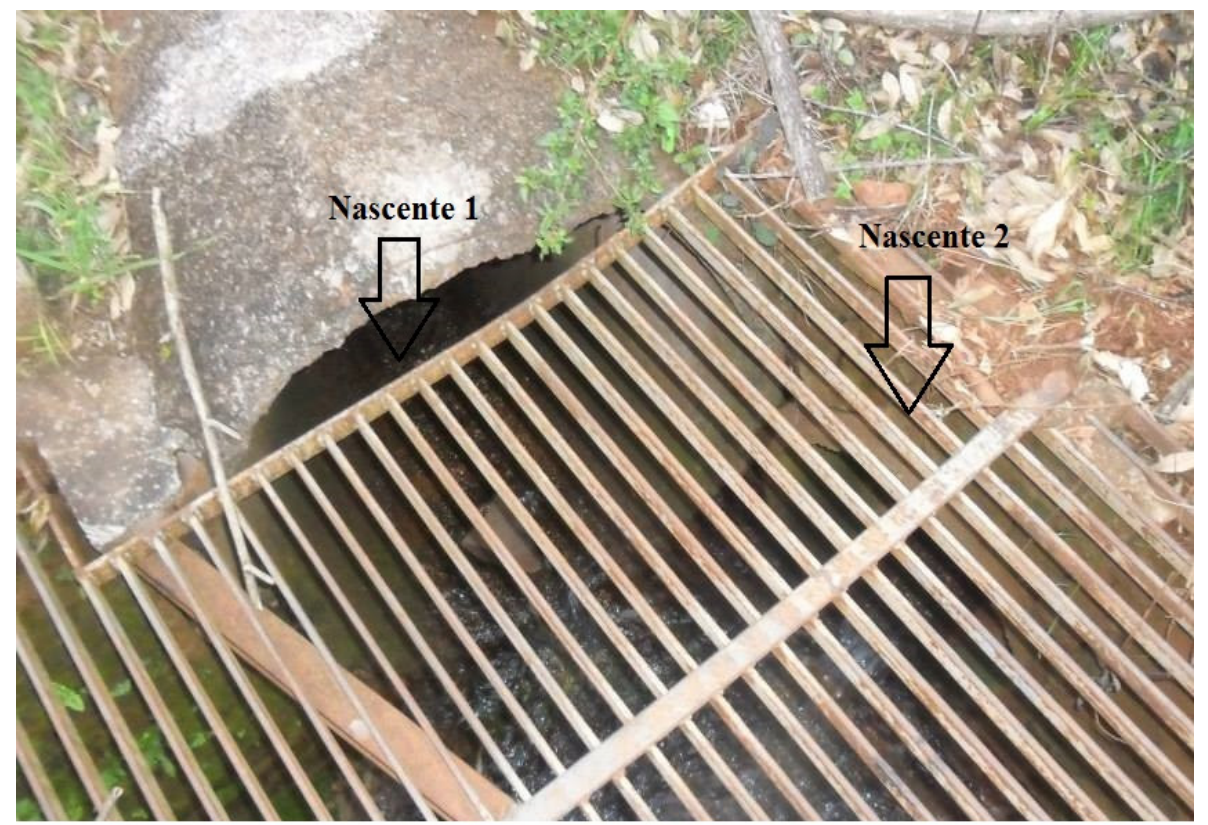

Figura 7: Encontro dos cursos d'água.

Fonte: Autor.

Alguns fatores relacionados às habitações que contribuem para aumentar a degradação do córrego são as condições precárias de rede de esgotos e sistema de drenagem no local, aliado também com a falta de conscientização ambiental por parte dos moradores, que ao longo do canal do córrego promovem o lançamento indiscriminado de efluentes domésticos no entorno e na água do córrego (ASSUNÇÃO, 2002).

A nascente 2, localizada rua Brasília encontra-se aterrada, com a construção de um edifício sob a mesma (Figura 6) .

O curso d'água, foi canalizado por uma tubulação e desemboca em um bueiro juntamente com a nascente 1 (Figura 7).

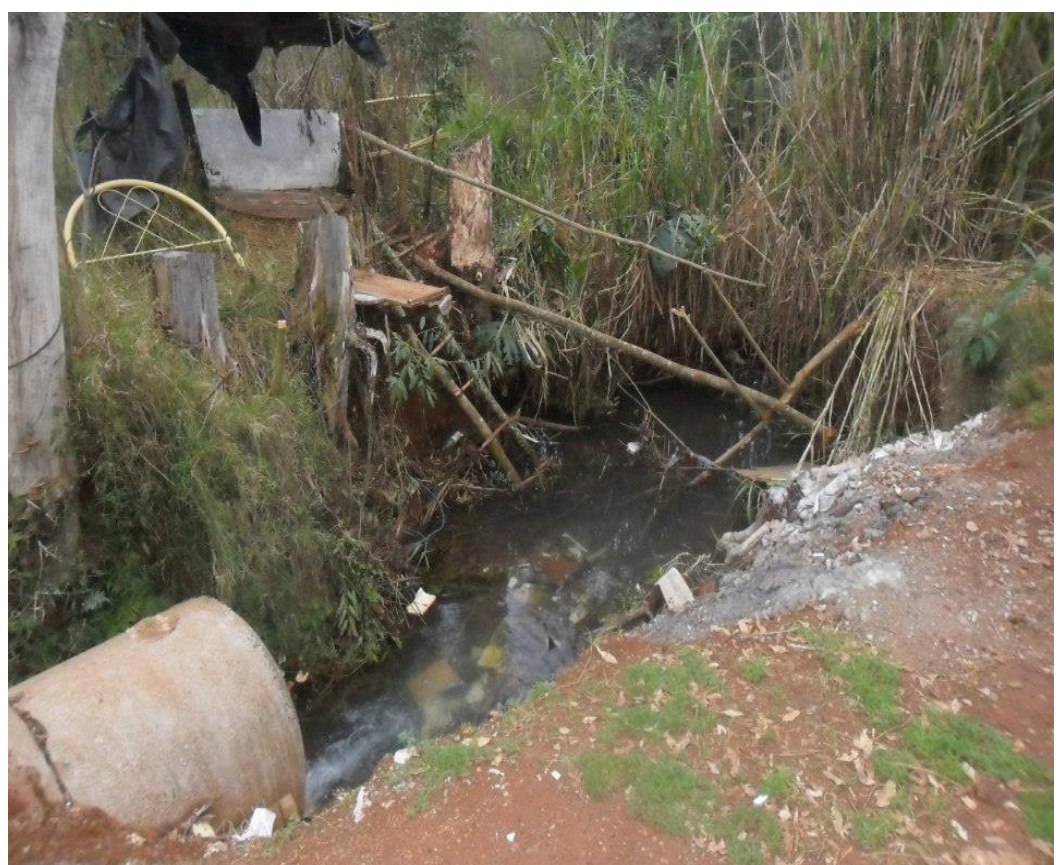

Figura 8: Desembocadura do curso d'água.

Fonte: Autor. 
Após o encontro dos cursos d'água, os mesmos são canalizados em uma tubulação e desaguam em um único duto com aproximadamente $70 \mathrm{~cm}$ de diâmetro (Figura 8). Os pequenos córregos que se formam com as nascentes, principalmente em dias chuvosos, carregam o lixo espalhado pela região acumulando em alguns pontos. Também sobre esses córregos perceberam-se alguns pontos onde a erosão pela água era bem acentuada e formavam "valetas" de quase um metro de altura, esta erosão ocorre pela falta da cobertura vegetal.

$\mathrm{Na}$ sequencia este duto junto com a drenagem superficial é desaguado em um pequeno córrego, onde pode-se observar descaso por parte da população, muita disposição de resíduos no local, criação de animais próximo ao curso d'água, com lançamento direto de dejetos no mesmo. Mais a frente, encontrou-se tubulações de esgoto residencial, também despejados no mesmo, conforme a figura 9 a seguir.

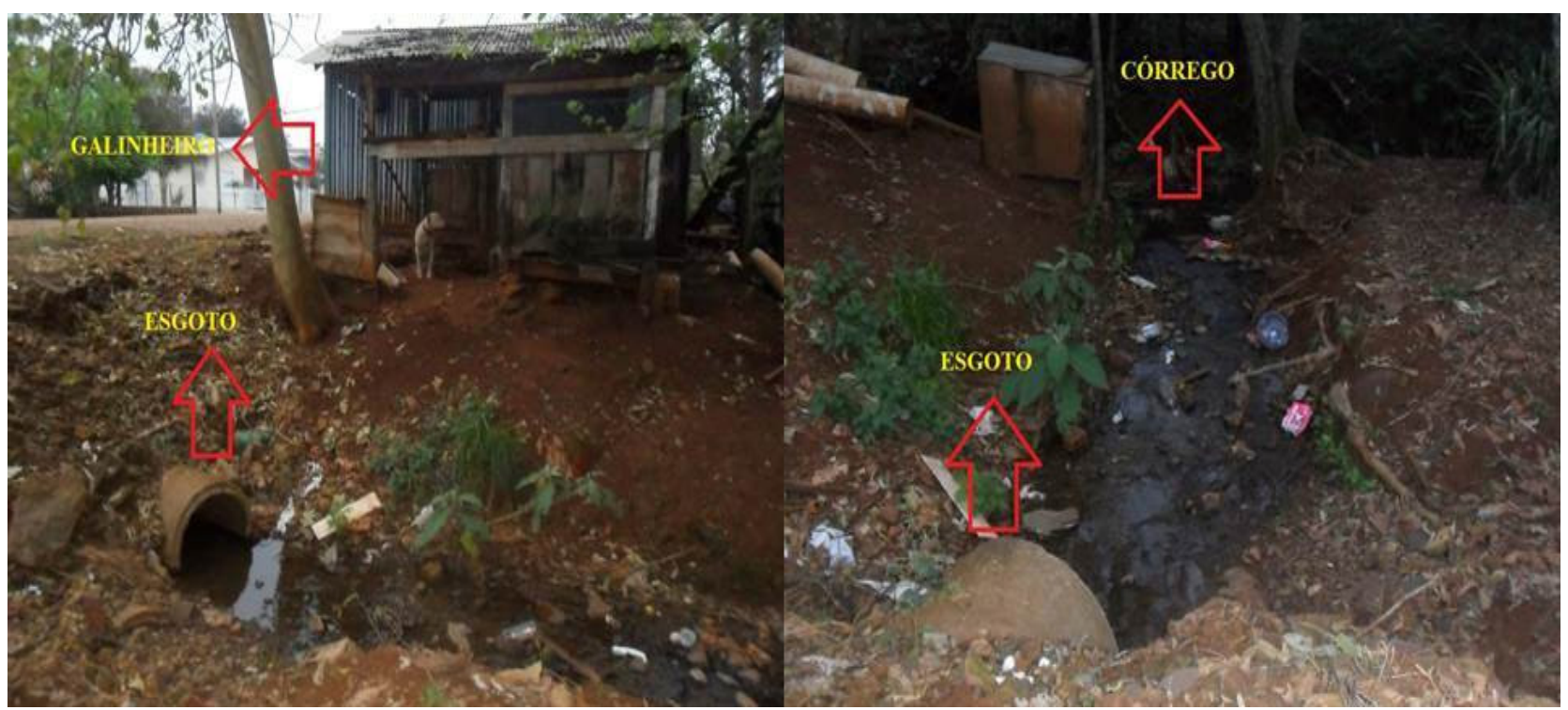

Figura 9: Poluição do curso d'água.

Fonte: Autor.

O curso d'água apresenta as mesmas características em todo o percurso.

\section{PROPOSTA}

O local de estudo apresenta uma grande necessidade de proteção do córrego Fátima em toda sua extensão, que vai desde as duas nascentes principais até a intersecção com outro afluente do Lajeado Pardo. De acordo com a Legislação Ambiental Brasileira, a medida correta a ser tomada seria a desocupação da área para posterior recuperação da APP, entretanto, esse processo causaria enormes problemas sociais.

Desta forma, as medidas a serem tomadas durante o processo de proteção, consistem no isolamento da área de forma a impedir a entrada de pessoas não autorizadas nas áreas em recuperação e também de animais, que no local podem continuar o processo de degradação.

Uma ação degradante nos trechos mencionados é a impermeabilização do solo, pela falta de vegetação nas márgens, elevando o volume do escoamento superficial, assim, a capacidade de suporte do córrego tornou-se pequena, levando a atual situação da erosão. Desta forma, propõem-se o reflorestamento das margens com o plantio de mudas de espécies nativas e frutíferas para recompor a paisagem original e resgatar a fauna do local.

Outra medida importante a ser tomada é a conscientização da população local bem como da gestão pública, para o recolhimento dos resíduos que já estão dispostos no local e prevenção de futuras ações poluidoras. 


\section{RESULTADOS ESPERADOS}

Com a implantação destas propostas para recuperação do córrego, espera-se que seja obtido sucesso no reflorestamento e recuperação da área de estudo bem como na conscientização das pessoas, preservando desta forma o recurso hídrico, a fauna e a flora. Assim proporcionando bem-estar e qualidade de vida a todos que vivem na região atualmente e para as futuras gerações.

\section{CONCLUSÃO}

Este estudo no córrego Fátima evidencia as consequências da falta de conscientização das pessoas e o descaso perante a conservação das Áreas de Preservação Permanente, que podem ocasionar a perda da biodiversidade, a degradação do solo e o desequilíbrio ecológico.

A simples observância da legislação ambiental brasileira bastaria para se perpetuar estas nascentes, mas por força da ostensiva demanda imobiliária, as referidas áreas encontram-se em locais desmatados, drenados, canalizados, aterrados ou simplesmente utilizados como deposição de entulhos e resíduos urbanos diversos.

A recuperação deste córrego, não se faz apenas pelas ações estabelecidas neste Artigo. Deve ser realizado um programa Municipal e Estadual a longo prazo, que vise a recuperação ambiental da área em um futuro próximo.

\section{REFERÊNCIAS}

ASSUNÇÃO, S. G. S. Riscos ambientais da ocupação urbana no entorno de águas superficiais - o caso do córrego Mingau, no bairro Parque Amazônia, em Goiânia - GO. Dissertação de mestrado. Brasília, 2002. $116 \mathrm{p}$.

BARUQUI, A. M.; FERNANDES, M. R. Práticas de conservação do solo. BeloHorizonte. Informe Agropecuário, Belo Horizonte. v. 1, n. 128. p. 5-69, ago. 1985. BRASIL. Estágio atual dos aspectos institucionais da gestão de recursos hídricos no Brasil. Política nacional de recursos hídricos, Brasília: Ministério do Meio Ambiente dos Recursos Hídricos e da Amazônia Legal / Secretaria Nacional dos Recursos Hídricos, p. 3-1, 1997.

FERNANDES, M.R. e SILVA, J. C. Programa Estadual de Manejo de Sub-MG. 1994. 24p

Bacias Hidrográficas: Fundamentos e estratégias - Belo Horizonte: EMATERFERNANDES, M.R. Controle Integrado de Erosão Hídrica: Proposta estratégica para Minas Gerais. IN: AÇÃO AMBIENTAL. UFV. Viçosa (MG). 1998.

GARBRECHT, J.; MARTZ, L.W. Digital elevationmodelissues in waterresourcesmodeling. ESRI, USERS CONFERENCE, 19., 1999, San Diego. Proceedings San Diego: 1999.

GUERRA, A.J.T.; CUNHA, S. B. Degradação ambiental. Geomorfologia e meio ambiente.In: CUNHA, S. B. Rio de Janeiro: Bertrand Brasil, 1996. p. 337-339.

LIMA, J. M. de. Relação entre erosão, teor de ferro, parâmetros físicos e mineralógicos de solos da região de Lavas (MG). 1987. 86 p. Dissertação (Mestrado em Solos e Nutrição de Plantas) - Escola Superior de Agricultura de Lavras, Lavras, MG.

LIMA, W. P. Princípios de hidrologia florestal para o manejo de bacias hidrográficas. Piracicaba, SP: ESALQ, 1986. $242 \mathrm{p}$.

ROSTAGNO, L. S. C. da. Caracterização de uma paisagem na área de influência do Reservatório da Usina 
Hidrelétrica do Funil, Ijaci-MG. 1999. 66 p. Dissertação (Mestrado em Solos e Nutrição de plantas) - Universidade Federal de Lavras,Lavras, MG.

SBCPD. Novo Código Florestal. Disponível em: <http://sbcpd.org/portal/images/stories/Novo-Codigo-Floresta-Lei-12651-2012.PDF>. Acesso em: julho de 2013.

SILVEIRA, A.L.L.Hidrologia: ciência e aplicação,Ciclo hidrológico e bacia hidrográfica- . In: TUCCI, C.E.M. (Org.). . São Paulo: EDUSP, 2001. p 35-51.

VALENTE, O.F. e CASTRO, P.S. Manejo de bacias hidrográficas. Informe Agropecuário, Belo Horizonte, v. 7 , n. 80, p. 40-45, mar. 1987. 